\title{
Discussion on applications of Internet of Things techniques to information engineering safety supervision
}

\author{
Ruxin $\operatorname{Tan}^{1, \text { a }}$ \\ ${ }^{1}$ Department of Information Science and Engineering ,Southeast University,Nanjing 210000,China \\ a594720299@qq.com
}

Keywords: Internet of Things; information engineering; safety; supervision

Abstract. Development of the information era has made "Internet of Things" a popular phrase. Its connotation has been gradually clarified, meaning connection between things via the Internet. Nowadays, the category of "things" keeps enriching. Development of Internet of Things has bred many new-and high-technologies. To supervise information engineering safety through the radio frequency identification (RFID), a branch of Internet of Things, can be more accurate and efficient. It can greatly improve practical schedule, quality and investment situations of information engineering. This paper further analyzes applications of the Internet of Things techniques in information engineering safety supervision.

\section{Introduction}

The development of Internet of Things has been impressive. After its emergence, it has found wide applications in all trades and industries. However, everything, when developed to certain period, will face a series of restrictions. The safety issues of Internet of Things are obstacles to its further development. The internal configuration of the Internet of Things system can be vividly likened to the combination of a mathematician, a management expert and a psychologist. Its executive capacity is self-evident. However, the powerful system will inevitably pose a threat to the country, society, enterprises and individuals. Therefore, it is of vital significance to analyze applications of Internet of Things in information engineering safety supervision.

\section{Internet of Things framework of information engineering safety supervision}

Ever since the 15 CPC National Congress, the Chinese government has given clear instructions about informationization construction. Under the guidance of correct policies, information development has reinvigorated science and technology. To put it simply, information engineering safety supervision means information safety control. The Internet of Things techniques can be used to probe safety problems, conduct management, achieve all-around information control and guarantee its safety. [1]

The Internet of Things framework of information engineering safety supervision is a part of the complete system formed for information protection. Obviously, the system includes not only the Internet of Things system and the information engineering safety supervision system, but also the intermediate structure connecting the two and the supervision platform system with Internet techniques.

Information engineering safety supervision is an integrated and complex field. On the one hand, the scope of supervision is extensive, and there are many control indexes. On the other hand, it is a long-term and continuous process. Therefore, there is a high requirement of the supervision quality. To achieve supervision of information safety issues during information engineering and reconstruction with the Internet of Things techniques is an efficient approach to get rid of traditional methods through new techniques. [2] 


\section{Overview of the Internet of Things techniques}

\subsection{Formation principles of the Internet of Things techniques}

The formation of a powerful technical system is attributable to multiple techniques. For example, the $3 S$ techniques are a combination of GIS, RS and GPS. The Internet of Things techniques are similar to the 3S techniques, which consists of multiple techniques, including item coding technique, wireless data communication technique and RFID technique. The formation principle is to achieve global tracking of each product through win-win cooperation between technique owners.

2.2 Characteristics of the Internet of Things techniques

Before the information era, the Internet had already been used as a medium. At that time, the emphasis was on mutual connection through the virtual network. After saying goodbye to the letter era, people called each other and sent messages to each other. However, now, text messages have been replaced by WeChat. As the era moves ahead, the Internet is faced with new requirements.

"Internet+" has been a late-mover in the recent two years. For example, "food+Internet=ele.me” , "traffic+Internet=Didi Taxi Service" and "bank+Internet=AliPay" — all these have brought convenience to people' s life. [3]

Internet of Things is an intelligent technique overtaking "Internet+" . Its goal is to realize office handling and learning home status synchronously. When one is still in a crowded bus, the electric cooker at home might have been started through remote control. One no long has to worry about parking, because Internet of Things techniques can book the parking position in advance.

Compared with the Internet and the "Internet+" , it can be seen that Internet of Things is intelligent and accurate. [4]

2.3 Development of Internet of Things

Internet of Things has a clear development goal, that is, to achieve super-intelligentization. Much work will be done by data processing, thus saving more time and energy for people.

\section{Applications of Internet of Things techniques in information engineering safety supervision}

3.1 Application status of Internet of Things techniques

Based on the above introduction, it can be seen that Internet of Things techniques are still in the developing period. Currently, these techniques have found applications in the following fields, including traffic, home furnishing, government administration, environment supervision, lighting, individual health and landscape lighting and supervision. The application case with the most constructive significance is that Internet of Things techniques have been applied to the logistics industry.

"Customs logistics supervision engineering" refers to unified supervision of vehicles and containers through the specialized customs Internet. After watching its demonstration, WEN Jiabao, the former Prime Minister, said, “This is Internet of Things.” In fact, in 1999, Internet of Things had been appeared in the US, and was called "Sensor Network" . However, its exploration was immature. China' s applications of Internet of Things techniques pushed Internet of Things to a new high.

The support of national and local governments has accelerated development of Internet of Things. There has also been a higher requirement of the safety of Internet of Things. Traditional measures cannot be copied to manage current Internet of Things techniques, but should be adjusted according to structural and systematic characteristics of Internet of Things.

The encryption mechanism and the node certification mechanism in Internet of Things are major measures to guarantee safety of Internet of Things techniques. Of course, there is the access control technology. However, new techniques are expected to cope with potential safety problems. 
3.2 Relationship between Internet of Things techniques and information engineering safety supervision

Similar to customs logistics supervision, information safety supervision also plays a supervising role, but its supervision objects are different. The former supervises tangible objects; while the latter supervises intangible information. However, in terms of their practical connotation, both belong to a safety status. Therefore, it is feasible to combine Internet of Things techniques with information engineering safety supervision. [5]

Operation of the Internet of Things system is a data integration process. During the process, data are exchanged and perceived to form a whole. It belongs to a scientific data integration model. The integration is vulnerable itself. When a node of data is viciously destroyed, it will be hard to distinguish the correct information. In the Internet of Things system, in order to enhance information safety protection, some protection mechanisms, such as the encryption system, are put in place.

3.3 Applications of Internet of Things techniques in information engineering safety supervision

3.3.1 Overview of the artificial neural network

The artificial neural network, as its name implies, means its design inspiration comes from humans' neural system. The neural system is a complex network itself. It contains special perceptions of humans. The neural network simulates some movement principles of the human brain so as to realize some perceptual functions.

The characteristic or the superiority of the artificial neural network is its self-study function similar to that of humans, which can recognize some images. Second, it has certain association and storage functions. However, the most important point is that it can quickly seek the optimal solution. This is a feedback network mechanism.

3.3.2 Transformation of the traditional neural network through Internet of Things techniques

By introducing the BP algorithm, the neural network can quickly distinguish data in information engineering so as to assist the information engineering safety supervision system in correct test of data. The improved neural network is not only alert in response, but also quick in training speed. The simulation experience can generate a large amount of samples learned by the neural network, clarify characteristics of the information engineering and then confirm the input of the neural network. Other requirements include scientific and reasonable network structure and accurate training algorithm. After learning, samples can form a neural network model which can recognize data.

3.3.3 Significance of Internet of Things to information engineering safety supervision

The development speed of Internet of Things techniques symbolizes the progress of the intelligentization development path. It is of vital significance to information engineering safety supervision. Applications of big data have made information more accurate; efficient and fast computing and integration has facilitated progress of information engineering and guaranteed its stability. Information safety means a lot to a country, enterprise and even individual. Therefore, combination of information engineering supervision and Internet of Things techniques is an important measure to guarantee information safety.

\section{Conclusions}

To sum up, through basic analysis of Internet of Things techniques and core issues related to information engineering safety supervision, the powerful system relying on Internet of Things techniques can be obtained to achieve multi-element and multi-aspect safety control of the whole information engineering. Through improvement of the traditional supervision network, the BP neural network, supervision intensity of information engineering is enhanced to cover engineering schedule, investment implementation situations and quality requirements. The efficient and reliable information engineering safety supervision mechanism can provide scientific guarantee for the smooth progress of information engineering. 


\section{References}

[1]YU Yan. A basic analysis of information engineering safety supervision and Internet of Things techniques[J]. Heilongjiang Science and Technology Information, 2014, 09: 122.

[2]NING Xin. The application of Internet of Things in construction safety management[J]. Building Economy, 2014, 12: 30-33.

[3]OU Wen. Study on Internet of Things techniques and their applications to agricultural production[D]. Kunming University of Science and Technology, 2015.

[4]CHEN Qizong. Applications and development of information technology in engineering supervision[J]. Science \& Technology Information, 2006, 21: 150.

[5]CHEN Biao. Research and application of bridge safety supervision techniques oriented towards Internet of Things and optical fiber sensing technology[D]. Wuhan University of Technology, 2011. 